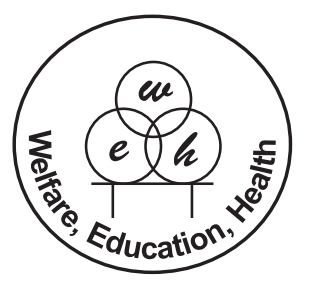

Journal of PharmaSciTech

ISSN: 22313788 (Print)

23214376 (Online)

\title{
Non-Canonical WNT Pathway in Breast Cancer and Breast Cancer StemCell Signalling
}

\author{
Partha Saha, Arunima Biswas* \\ Department of Zoology, University of Kalyani, Kalyani, Nadia, West Bengal, Pin:741235, INDIA.
}

*Correspondence: arunima10@gmail.com ( Tel.: +91 9836793528)

\section{Abstract}

Breast cancer is the most common cancer in women all over the world. Though various treatment regimens are available for breast cancer, treatment of breast tumor is still a challenge. Breast cancer can be of different types and like many other cancers, it is a stem cell disease.

Presence of stem cell might be the cause of therapy failure due to their characteristic feature of drug resistance. So researchers now focus in regulating breast Cancer Stem Cells (brCSCs). Wnt signalling is a major signalling pathway involved in regulating tumour morphogenesis. Wnt signalling pathways have been categorized into: canonical Wnt pathway and non-canonical Wnt pathway.

Both canonical and non-canonical pathways play major role in maintenance of stemness in brCSCs. Since canonical pathway of Wnt signalling has been studied in great detail, studying non-canonical pathway and its signalling mechanisms will provide interesting insights to control breast cancer and its stemness properties. This review will focus on the recent and the various research aspects on the non-canonical pathway in regulating brCSCs.

Keywords: Wnt signalling, Non-canonical Wnt pathway, breast cancer, stemness, breast Cancer Stem Cells (brCSCs).

\section{Introduction}

Breast cancer is the most common type of cancer in women, representing more than 5,22,000 deaths along with 1.7 million new cases annually throughout the world [1-2]. Researches elucidate that tumours are comprised of heterogeneous cellular populations bearing differentiated and undifferentiated masses of cell. Herein it was observed that undifferentiated tumour cells owing to its drug resistance and tumour relapse, being considered to be the most effective target to get rid of cancer and its relapse [3-4].

The stem cell concept in cancer is obtained from embryonic stem cell (ESCs) and adult stem cell. Researchers have successfully modified somatic cells into cells that bears epithelial stem cell like characteristics known as induced Pluripotent Stem Cells (iPSCs) [5]. Alteration in gene expression and by symmetry of their cell division cancer stem cells (CSC) can be differentiated from other cells [6]. In contrast to normal cancer cell as few as $100 \mathrm{CSC}$ can form tumour in non-obese diabetic/severe combined immune-deficient (NOD/SCID) mice [7]. To synchronize cell fate determination and survival, these cells inhabit specialized niches where they merge various environmental and intrinsic signalling inputs from hedgehog, notch and Wnt pathways [8]. The ability to self-renew themselves makes them susceptible for accumulating mutations that may cause initiation of tumour. Heterogeneous entities of cell type are found in several type of cancer and tumour initiation capacity seems to be conferred by a subpopulation of tumour cells that triggers tumour growth. As these cells possess self-renewal capacity and also exhibit multi-differentiation potential, they are often mentioned as cancer stem cells (CSCs). Reactivation of embryonic developmental pathway is one of the basic features of cancer cells [9] [Figure 1].

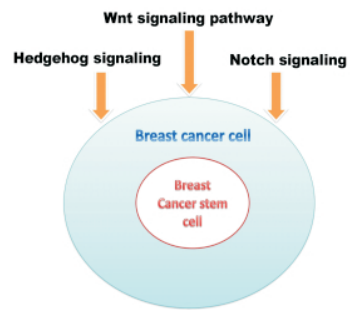

Figure 1: Cellular signalling pathways regulating breast cancer cells and breast cancer stem cells

http://www.pharmascitech.in
Wnt signalling modulates developmental phenomenon in cells and promotes symmetric cell division in stem cells [10]. Altered Wnt signalling maintains stem cell characteristics of brCSCs [11]. Evidences suggest that inhibition of Wnt1 in $\mathrm{CD}_{4} 4^{+} \mathrm{CD} 24^{-} \mathrm{ALDH} 1$ cells alter their phenotype by reducing their metastatic potential and ability to form tumour in-vitro as well as in-vivo conditions [12]. An autocrine mechanism kept Wnt signalling remains active in breast cancer [13]. During ex-vivo assays, mammosphere formation in suspension culture gives opportunity to study stem cells and to analyze their signalling pathways [14-15]. It was found that a noncanonical Wnt ligand Wnt5a can induce formation of mammosphere with the help of ror2 and activation of JNK pathway [16].

\section{Breast cancer and breast cancer stem cell}

Conversion of normal somatic epithelial cells into immortalized metastatic cells requires deregulation of multiple cellular processes including aberration in expression of many oncogenes and tumour suppressor genes. Deregulation of more than thousands of genes has been reported in breast cancer alone [17-18]. Western blot analysis of protein associated with various signal transduction pathways allowed detection of aberrant pathways with aspects of breast cancer. Based on gene expression studies and immunohistochemistry breast cancer cell lines are classified into estrogen receptor/ progesterone receptor (ER/PR) positive, human epidermal growth factor receptor2 (HER2) amplified, triple negative and basal like and luminal subtypes. The basal like cellular subtype are further categorize into basal A and basal B types. These basal B sub-type of cells show high invasiveness and retain $\mathrm{CD} 44^{+} / \mathrm{CD} 24^{-10 w}$ markers on their cell surface that resemble with certain population of tumorigenic stem cell [19-20].

In1994, a study of human acute myeloid leukaemia first suggested the role of stem cells in cancer [21]. According to some researchers, about $25 \%$ of cancer cells have properties of CSC [22]. brCSCs were first isolated from solid tumours in 2003 [7]. This small subset of cells has the capacity of self-renewal, high proliferation rate, ability to generate heterogenic lineages of cancer cells and might be the reason for therapy failure due to over expression of $A B C$ drug transporters, increase DNA damage response and moderation of reactive oxygen 
species [23-26]. The ability of resistance to DNA damage has been obtained from their liability to mitochondrial respiration, sustained by higher mitochondrial reactive oxygen species and enhanced oxygen consumption [27]. This self-renewal and proliferating ability make these stem cells susceptible to accumulate mutation thereafter leads to tumour initiation [28]. This small subset of cells might be the cause for relapse in many cancers, such as in triple negative breast cancer [29].

By using cytokeratin staining we can differentiate mammary gland in two distinct layers the luminal and basal compartments. Cytokeratin 8 and 18 displays positive staining in luminal cells whereas cytokeratin 5 and 6 stained basal cells [30]. In basal compartment the mammary stem cells (MaSCs) remain [31]. These MaSCs can give rise to both basal and luminal cell in development [32]. Allogeneic transplantation of MaSCs into mammary fat pads can give rise to de novo mammary glands [33].

CSC may originate by mutation of normal stem cell [34]. According to the "misplacement somatic cell theory" CSCs may originate from misplacement of somatic cells de novo [35]. An alternative theory states that acquisition of mesenchymal traits and stem cell markers by cancer cells through a process of epithelial mesenchymal transition also considered significantly vital in CSC origin [36]. Indulgent expression mesenchymal transcriptional factors like zinc finger protein SNAI1, zinc finger E-box binding homeobox $1 / 2$ and Twist-related protein 1/ 2 (SNAIL1/2, ZEB1/2, and TWIST1/2) lead to therapy resistance in brCSC form conventional drug used in treatment of breast cancer such as paclitaxel, adriamycin, and doxorubicin etc [37-38].

Various cell surface markers have been used to identify and to isolate CSC from different tumors. Cell surface markers of CSC are highly tissue specific and even differentially expressed in different tumour sub-types. Breast cancer stem cells are characterized by expression of $\mathrm{CD}_{4}{ }^{+} \mathrm{CD} 24^{-}{ }^{- \text {low Lineage }}$ and ALDH $[7,39]$.

Breast cancer, breast cancer stem cell and wnt signalling pathway

Development of mouse mammary tumor through insertional activation of int 1 by MMTV demonstrates the role of Wnt in breast cancer progression [40]. However, Wnt1 implication not has been done in case of human breast neoplasm, it has been reported that altered Wnt gene expression which subsequently leads to deregulation of downstream protein component of this pathway seems to be prominent in respect to almost all breast cancer subtypes [41]. Mediators of this pathway such as $\beta$-catenin, Wnt5a, tumour suppressor protein APC etc. are act as proto-oncogene and their functional redundancy leads to tumor development and progression [42-43].

A single founding cell can develop cancer and due to the self-renewal capability of CSC these cells are the superior target for cellular transformation. These CSC populations reside in specified niches where they determine cell fate and maintain tissue homeostasis through various signalling pathways [44]. WNT pathway plays a key role in stem cell self-renewal and preservation of an undifferentiated state [45]. Altered Wnt signalling in brCSC derives breast tumorigenesis [11]. Both types of Wnt signalling canonical and noncanonical can induce stem cell growth in mammosphere culture [46]. WNT activity and CSC phenotypes are linked through a WNT reporter in various human tumour types such as lung, gastric and breast cancer [47]. Stemness of cell is chiefly depending on TERT gene that maintains long telomerase region. Binding of $\beta$-catenin to the promoter region of TERT gene is responsible for complementing its transcription. Hence this links Wnt signalling pathway with stem cell alimentation [48].

Consequently, Increase WNT ligand production in breast cancer cell line stabilizes $\beta$ catenin [49]. In contrast to canonical Wnt ligand that is upregulated in cancer cell non-canonical Wnt ligands become down regulated [50]. Herein a frizzled related protein encoding factor sFRP1 expression is lost in $46 \%-80 \%$ of breast cancers and is syndicated with poor prognosis [51] [Figure 2].

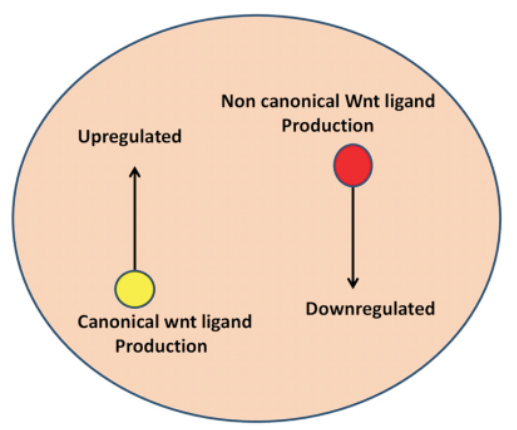

Figure 2: Wnt ligand production in breast tumour

\section{Role of non-cononical pathway in regulating breast cancer and breast cancer stem cells}

However, in recent past it was observed that a few $\beta$-catenin and GSK3 independent pathway play some crucial role in tumour biology. Abnormality in non-canonical Wnt pathway has seen in many types of tumour.

Researchers have found that in a highly invasive breast cancer phenotype triple negative breast cancer and in CSC unusual activation of c-Jun $\mathrm{N}$-terminal kinase in non-canonical pathway lead to an increase in the metastatic behaviour [52].

These pathways function through activating various downstream mediators such as calcium/calmodulin dependent kinase II (CamKII) and protein kinase $C(\mathrm{PKC})$, phospholipase $\mathrm{C}(\mathrm{PLC})$, phosphodiesterase (PDE), lastly Jun-N-terminal kinase (JNK) and small GTPbinding proteins. Calcium has been acting as a second messenger, perhaps in all these pathways. These cellular cascades regulate gene expression through transcription factors activating protein 1 (AP1) and nuclear factor of activated T cells (NFAT).

Both canonical and non-canonical pathway possesses some common component at beginning but differ in their downstream mechanism. This sharing of components allows crosstalk between two pathways [53-54].

\section{Different non-canonical wnt pathways in breast cancer}

Non canonical Wnt pathway basically divided into two major categories - The planar cell polarity (PCP) pathway and $\mathrm{Wnt} / \mathrm{Ca}^{++}$ pathway. Both of which function through interaction of non-canonical Wnt ligand with frizzled receptor (Fzs) but neither Lrp5 nor Lrp6 is required as co-receptor [55-56].

\section{Planar cell polarity pathway}

Planer Cell polarity Pathway regulates cell polarity by regulating actin polymerization. First of all a Wht ligand binds with frizzled heterodimeric receptor. Thereafter Wnt-FZD complex activate Dishevelled (Dsh) to trigger downstream signalling cascade. Dishevelled then binds with Dishevelled-associated activator of morphogenesis 1 (DAMM1). Activated DAMM1 then stimulate small GTP binding Protein Rho which further recruits Rho-associated kinase (ROCK). Thereby regulating actin and profilin cytoskeleton. Activated disheveled by formation of DSH-RAC1 complex also helps in expression of many genes (AP1,C-jun) associated with cell polarity, adhesion, shape through activation of JNK pathway [57-58] [Figure 3]. 


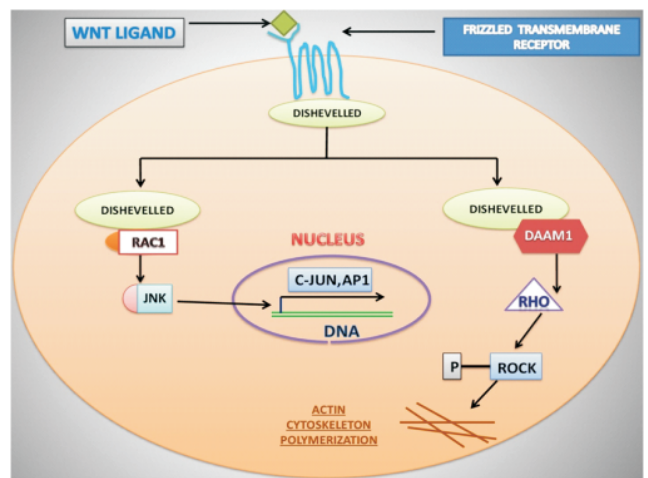

Figure 3: Planer cell polarity pathway of non-canonical Wnt signalling

\section{Wnt Ca ${ }^{++}$pathway}

WntCa ${ }^{++}$regulates gene expression through intracellular $\mathrm{Ca}^{++}$ signalling pathway. WNT 5a and WNT5b mostly act as major ligand in this pathway. Here dishevelled along with trimeric $\mathrm{G}$ protein cleaved $\mathrm{PIP}_{2}$ into $\mathrm{IP}_{3}$ and DAG. IP3 regulates release of $\mathrm{Ca}^{++}$from ER whereas DAG activates cell division control protein homolog 42 (cdc42). Cellular calcium transcribe target genes through activation of calcineurin and CaMKII. Calcineurin mediate transcription of nuclear factor of activated T cells (NFAT). CaMKII stimulate mitogen-activated protein kinase (MAPK) which leads to activation of TGF $\beta$-activated kinase (TAK1) and finally NLK that suppress Wnt/ $\beta$-catenin signalling pathway [59] [Figure 4]

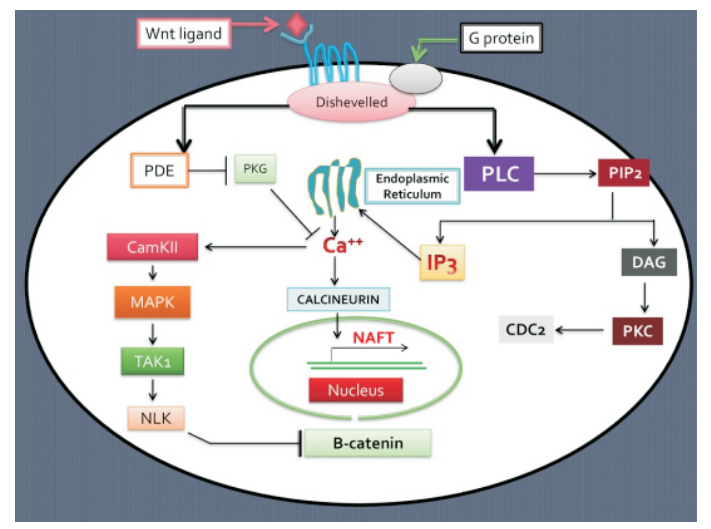

Figure 4: $\mathrm{Ca}^{++}$dependent Wnt signalling pathway

\section{Non-canonical Wnt receptors and proteins}

Frizzled-3 (FZD3) and Frizzled-6 (FZD6) act as receptors, whereas ROR1, ROR2 and PTK7 are functioning as co-receptors [60-63]. VANGlikel/Strabismus2 (VANGL1/STB2) and VANG-like2/Strabismusl (VANGL2/STB1) are the transmembrane proteins [64-65].

Dishevelled-1(DVL1), Dishevelled-2 (DVL2) and Dishevelled-3 (DVL3) are human homologs of dishevelled protein [66-67].

\section{Non-canonical Wnt ligands and breast cancer}

Among several Wnt ligands Wnt4, Wnt5a, Wnt11 are important noncanonical Wnt proteins [68-70]. Till date not much researches have been done to understand the roles of Wnt4 in breast cancer. Mutation of Wnt5 and Wnt11 genes in the zebrafish manifest convergence extension phenotypes, suggesting Wnt do act as non-canonical Wnt ligands in this system.

\section{Role of Wnt5a, Wnt5b and Wnt7a}

A non-canonical Wnt ligand Wnt5a is evolutionary conserved and uses a calcium dependent pathway to direct cell motility and invasiveness [71]. Wht 5a and Wnt5b act as proto-oncogene in various cancers including breast cancer(72). Furthermore Wnt $5 a$ play crucial role in maintaining function of stem cell, alienate canonical Wnt proteins and macrophage driven malignant invasion [72-74]. It was found that Wnt5a can be used as a tumor suppressor in C57MG mammary epithelial cell through anti-sense Wnt5a reproduced Wnt1-mediated epithelial cell transformation [75]. Loss of Wnt5a confers more aggressive tumour phenotype which leads to poor prognosis in human breast cancer patient [76]. Wnt5a can trigger mammosphere formation in-vitro with the help of ror2 and jun$\mathrm{N}$-terminal kinase (JNK) [47]. Moreover, Wnt5a can antagonize canonical signalling pathway through some definite mechanism. Presence of SMAD binding sites in Wnt5a promoter and regulation of Wnt5a by TGF- $\beta$ should be play crucial role in further research [77]. TGF- $\beta$ signalling pathway function through SMAD4 mediator that comprises over 40 growth and differentiation factors such as activin, inhibin which play diverse function in regulating proliferation, differentiation and apoptosis. Generating SMAD4 mutant mice through Cre-loxP approach, help to figure out TGF- $\beta$ /SMAD4 signalling pathway during mammary tumorigenesis [78] .Cre recombinase can bind with ligand binding domain of estrogen receptor and form CreER recombinase. Inactivated CreER recombinase can be activated by using a synthetic estrogen receptor ligand i.e, tamoxifen or 4-hydroxy tamoxifen. Combination of both CreER and tamoxifen can regualate tissue specific gene expression and also help in drug designing and development [79]. MMP3 secreted by mammary epithelial cell annihilate the inhibitory role of non-canonical Wnt pathway through WNT5b and induce canonical signalling pathway [80]. WNT5a participate in non-canonical pathway through binding with Receptor Tyrosine Kinase-Like Orphan Receptor (ROR) a family of trans-membrane proteins [61].

Though Wnt5a is primarily a non-canonical Wnt ligand it can also influence canonical pathway by stabilizing $\beta$-catenin [81]. It is also evident that $\mathrm{Wnt} 5 \mathrm{a}$ is upregulated and stimulate multidrug resistance ability through stabilizing $\beta$-catenin by activation of PKA pathway in many cancer cell lines, such as MES-SA/Dx5 and MCF7/ADR2 cells. In context of clinical breast cancer tissue Wnt5a is positively correlates with $A B C B 1$ and VEGF expression [82].

It was observed that Wnt 5a compete with Wnt3a to bind with frizzeld2 receptor thereby reduces Wnt3a dependent accumulation of $\beta$ catenin in cytosol which confirms its role in inhibiting $\beta$ catenin dependent Wnt pathway [83]. In this context planer cell polarity pathway leads to Wnt7a stimulated symmetric expansion of satellite stem cells through planer polarization [10].

\section{Role of "ROR" receptor in breast cancer}

ROR was first discovered in neuroblastoma cell line is a $130 \mathrm{Kda}$ protein has $58 \%$ amino acid similarity with MUSK and Trk family receptors. ROR family receptor has two subtypes ROR1 and ROR2. Human ROR1/2 bears an extracellular immunoglobulin-like (IG) domain at the amino terminus end. A cysteine-rich Frizzled domain (FZD), and a Kringle trans-membrane domain (KRD).

DNA microarray analysis of triple negative breast cancer cell has shown that ROR1 which is associated with poor prognosis are present only in breast cancer cell but not in normal breast cell [84]. ROR2 is present in both TNBC and in non TNBC. Patients with breast cancer detecting with ROR2 expression have low survivor capacity than patients who are lacking of it. Suppression of ROR2 inhibits Wnt signalling by blocking TCF/LEF transcription [85].Through transmembrane frizzled domain Both Wnt5a and Wnt5b binds at the carboxy terminus end of human ROR1/2 receptors $[53,61]$. ROR1 
seems to be highly important in regulating EMT genes, SNAI1, SNAI2, ZEB1, TWIST1/2 and vimentin in triple negative cell line [86]. Ability of cellular migration can be suppressed in MDA-MB-231 by Silencing of ROR1 by shRNA.It also reduced bone and lung size in xenografts [87].

\section{Role of VANGL1 and VANGL2 in breast cancer}

Two major Scaffolding protein components of PCP cycle VANGL1 and VANGL2 are differentially expressed in different cancer cell. Researchers found that VANGL and non-canonical Wnt ligand Wnt11 which signal through PCP is transcriptional target of oestrogen receptor [88-89]. This interference between ER and PCP signalling should provide valuable insight for future research on breast cancer prognosis. Cancer Genome Atlas Project (TCGA) analyse that VANGL1 is up-regulated in $5 \%$ of invasive breast carcinoma, whereas VANGL2 is over expressed in $24 \%$ of invasive breast carcinoma [90-91].

Migration of aggressive human breast cancer cell line MDA-MB-231 was inhibited through knock down of VANGL1, suggests the role of VANGL signalling in motility of breast cancer cell [92]. It was also found that VANGL1 increase risk of tumour recurrence in certain breast cancer patients, notably in oestrogen receptor positive patients [93]. Microarray analysis suggests oestrogen down regulate VANGL1 in pituitary, whereas it up-regulates VANGL2 in breast cancer cell line MCF7 [94]

VANGL2 is associated with apical basal polarity in several developmental processes and maintain satellite stem cell regeneration in muscle cell. VANGL2 can act as a tumour suppressor in many tumour types by inhibiting canonical Wnt signalling pathway by displacing dishevelled from cytosol to plasma-membrane [10,95-96].

Deregulation of VANGL1 and VANGAL2 in various breast cancer subtypes shows involvement of PCP component in these subtypes of breast cancer and effect of oestrogen in their regulation in-context to the microenvironment of definite tissue type.

Now-a-days researchers now also investigate various downstream effector proteins of VANGL, Such as expression pattern of PRICKLE1 and SCRIBBLE proteins in breast cancer cell line. Knockdown of PRICKLE1 by L-conditioned media reduces metastasis in breast cancer tissue sample [97], whereas SCRIBBLE which is a known tumour suppressor in humans is found to be decreased in breast tumours [98] [Figure 5].

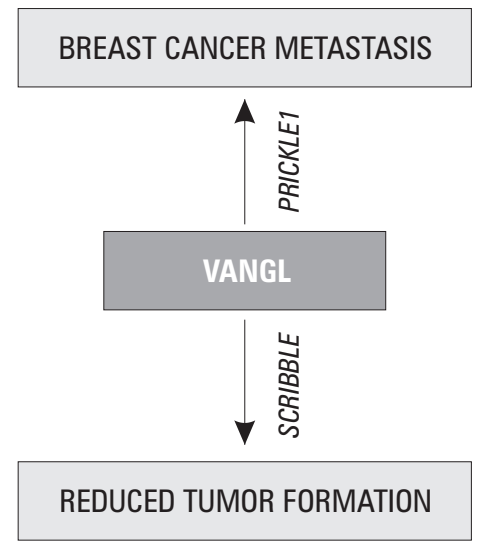

Figure 5: VANGL in Breast Cancer

\section{Role of Phsphodiesterase (PDE) in breast cancer}

In an alternative non-canonical Wnt pathway if $3^{\prime}, 5^{\prime}$-cyclic nucleotide phosphodiesterases (PDEs) activate it hydrolyse 3'-phosphodiester bond of cyclic guanylate monophosphate (cGMP) converting it into biological inert GMP derivative. This reduction of cellular cGMP concentration in turn inhibits activation of PKG which ultimately blocks release of ca + + from endoplasmic reticulum (ER).
It has been found that well characterize cGMP specific PDE isoform phsphodiesterase type 5(PDE5), phosphodiesterase type 6(PDE6) and PDE9 concentration level become elevated in association with tumour grade and their invasive potential in several breast cancer cell lines and tissue [99]. So, suppression of PDE activity by medically approved PDE inhibitors is now a prime emphasis of oncologist.

\section{Evidences of Non-Canonical pathway in BCSC}

Stem like cell in cancer have ability to sphere formation in suspension culture. Thus researchers has been suggested mammosphere formation as an indicator of obtaining cells that bear stem like properties in mouse and human mammary cell lines as well as in primary tissue culture. Mammosphere provides valuable insight to encompass various signalling pathways regulating their behaviour. Investigation revealed Wnt ligand Wnt5a along with ROR2 activate JNK pathway which leads to formation of mammosphere. So Wnt5a which is primarily a known non-canonical ligand can form mammosphere and provide confirmatory evidence to the role of noncanonical Wnt pathway in stem like cell in breast cancer.

\section{Conclusion}

Though the molecules were discovered in the recent past 20, Wnts are popular molecules in research and are studied in great detail. The reason behind this interest is due to importance of Wnt signalling in maintaining the genetic, biochemical and developmental processes at a large scale. But the most important reason behind this is the fact that mutations in Wnts or Wnt signalling components have been associated with diseases that cover a wide spectrum of afflictions, from arthritis to schizophrenia. Lastly, Wnts appear able to expand, or perhaps maintain, certain undifferentiated stem cell populations as well is known to be one of the probable targets to track and study cancer stem cell population. Wnt proteins hold potential as agents to manipulate multipotent cells in vitro and could provide a key element in developing stem cell-derived tissue replacement therapies. Though a lot has been studied about the canonical Wnt signalling pathway in association to its role in tumor formation, scanty information are available in the context of non-canonical Wnt signalling and its role in tumor progression.

The purpose of the study is to characterize breast cancer in respect to breast cancer cell and cancer initiating cell which can also be termed as cancer stem cells and to focus on signalling pathways with specific insight on $\beta$-catenin-independent Wnt signalling. Mechanism and component of the pathway, their cellular function and status in context to normal and altered tumor cell are also elucidated. Through this review it is found that non-canonical Wnt components become deregulated or shows altered expression in respect to cancer initiation and progression. Herein different aspects of possible target can be identified with respect to grow novel strategies and to develop therapeutics which can resolve prevailing complication associated with treatment of breast cancer. The association of the $\beta$-catenin-independent Wnt signalling in maintaining the stemness of the brCSCs have not been fully elucidated and in depth understanding of the same may provide hints to develop possible therapeutic targets associated with the stoppage of the tumor regrowth and relapse.

\section{Conflict of interest}

The authors declare that they have no competing interest.

\section{References}

[1] Oliveira LR, Jeffrey SS, Ribeiro-Silva A. HistolHistopthol 2010; 25:371-85. [2] Torre LA, Bray F, Siegel RL, Ferlay J, Lortet-Tieulent J et al. Global cancer statistics, 2012.CA Cancer J Clin, 2015; 65:87-108.

[3] Pierce GB. Relationship between differentiation and carcinogenesis. JToxicol Environ Health 1977; 2:1335-1342.

[4] Clarke MF, Dick JE, Dirks PB, Eaves CJ, Jamieson CH et al.Cancer stem cells:perspectives on current status and future directions: AACR Workshop on cancer stem cells. Cancer Res 2006; 66:9339-44. 
[5] Takahashi K, Yamanaka S. Induction of pluripotent stem cells from mouse embryonic and adult fibroblast cultures by defined factors. Cell 2006; 126:66376.

[6] Rosen JM, Jordan CT. The increasing complexity of the cancer stem cell paradigm. Science 2009; 324:1670-3.

[7] I-Hajj M, Wicha MS, Benito-Hernandez A, Morrison SJ, Clarke MF. Prospective identification of tumorigenic breast cancer cells. ProcNatlAcadSci USA 2003; 100:3983-8.

[8] Reya T, Clevers H. Wnt signalling in stem cells and cancer. Nature 2005; 434:843-50.

[9] De Sousa E, Melo F, Vermeulen L. Wnt Signalling in Cancer Stem Cell Biology. Cancers 2016; 8:60.

[10] Le Grand F, Jones AE, Seale V, Scime A, Rudnicki MA. Wnt7a activates the planar cell polarity pathway to drive the symmetric expansion of satellite stem cells. Cell Stem Cell 2009; 4:535-47.

[11] Howard B, Ashworth A. Signalling pathways implicated in early mammary gland morphogenesis and breast cancer. PLoS Genet 2006; 2:e112.

[12] Jang GB, Kim JY, Cho SD, Park KS, Jung JY, et al. Blockade of WNT/ $\beta$ catenin signalling suppresses breast cancer metastasis by inhibiting CSC-like phenotype. Sci Rep 2015; 5:12465.

[13] Giles RH, Van Es JH and Clevers H. Caught up in a WNT storm: WNT signalling in cancer. BiochimBiophysActa - Rev Cancer 2003; 1653:1-24.

[14] Dontu G, Abdallah WM, Foley JM, Jackson KW, Clarke MF, et al. In vitro propagationand transcriptional profiling of human mammary stem progenitor cells.Genes Dev 2003; 17:1253-1270.

[15] Liao MJ, Zhang CC, Zhou B, Zimonjic DB, Mani SA, et al. Enrichment of a population of mammary gland cells that form mammospheres and have in vivo repopulating activity. Cancer Res 2007; 67:8131-8.

[16] Many AM, Brown AM. Both Canonical and Non-Canonical Wnt Signalling Independently Promote Stem Cell Growth in Mammospheres. PLoS ONE 2014; 9:e101800.

[17] Hyman E, Kauraniemi P, Hautaniemi S, Wolf M., Mousses S, et al. Impact of DNA amplification on gene expression patterns in breast cancer. Cancer Res 2002; 62:6240-5.

[18] Pollack JR, Sorlie T, Perou CM, Rees CA, Jeffrey SS, et al. Microarray analysis reveals a major direct role of DNA copy number alteration in the transcriptional program of human breast tumors. Proc. Natl. Acad. Sci. USA 2002; 99:12963-8.

[19] Care LA, Perou CM, Livasy CA, Dressler LG, Cowan D, et al. Race, Breast Cancer Subtypes and Survival in the Carolina Breast Cancer Study. JAMA 2006; 295:2492-502.

[20] Park SY, Lee HY, Li H, Shipitsin M, Gelman R, et al. Heterogeneity for stem cell-related markers according to tumor subtype and histologic stage in breast cancer. Clin Cancer Res 2010; 16: 876-87.

[21] Lapidot T, Sirard C, Vormoor J, Murdoch B, Hoang T, et al. A cell initiating human acute myeloid leukaemia after transplantation into SCID mice. Nature 1994; 367:645-8.

[22] Kelly PN, Dakic A, Adams JM, Nutt SL, Strasser A. Tumor growth need not be driven by rare cancer stem cells. Science 2007; 317:337.

[23] Simons BD, Clevers H. Strategies for homeostatic stem cell self-renewal in adult tissues. Cell 2011; 145:851-62.

[24] Bao S, Wu O, McLendon R.E, Hao Y, Shi O, et al. Glioma stem cells promote radioresistanceby preferential activation of the DNA damage response. Nature 2006; 444:756-60.

[25] Diehn M, Cho RW, Lobo NA, Kalisky T, Dorie MJ, et al.Association of Reactive Oxygen SpeciesLevels and Radioresistance in Cancer Stem Cells.Nature 2009; 458:780-3.

[26] Lou H and Dean M. Targeted therapy for cancer stem cells: the patched pathway and ABC transporters. Oncogene 2007; 26:1357-60.

[27] Peiris-Pages M., Martinez-Outschoorn UE, Pestell RG, Sotgia F, Lisanti MP. Cancer stem cell metabolism. Breast Cancer Res 2016; 18:55.

[28] Visvader JE. Cells of origin in cancer. Nature 2011; 469:314-22.

[29] Pogoda K, Niwinska A, Murawska M, Pienkowski T. Analysis of pattern time and risk factors influencing recurrence in triple-negative breast cancer patients. Med Oncol 2013; 30:388.

[30] Taylor-Papadimitriou J, Stampfer M, BartekJ, Lewis A, Boshell M, et al. Keratin expression in human mammary epithelial cells cultured from normal and malignant tissue: relation to in vivo phenotypes and influence of medium. J Cell Sci 1989; 94:403-13.

[31] Keller PJ, Arendt LM, Skibinski A, Logvinenko T, Klebba I, et al. Defining the cellular precursors to Human breast cancer. Proc Natl Acad Sci USA 2012; 109:2772-7.

[32] Rios AC, Fu NY, Lindeman GJ, Visvader JE. In situ identification of bipotent stem cells in the mammary gland. Nature 2014; 506:322-7.

[33] Shackleton M, Vaillant F, Simpson KJ, Stingl J. Smyth GK, et al. Generation of a functional mammary gland from a single stem cell. Nature 2006; 439:84-8.

[34] Hartwig FP, Nedel F, Collares T, Tarquinio SB, Nör JE. Oncogenic somatic events in tissue-specific stem cells: a role in cancer recurrence? Ageing Res Rev 2014; 13:100-6.

[35] Wang RA, Li ZS, Zhang HZ, Zheng PJ, Li QL, et al. Invasive cancers are not necessarily from preformed in situ tumours: an alternative way of carcinogenesis from misplaced stem cells. J Cell Mol Med 2013; 17:921-6.

[36] Mani SA, Guo W, Liao MJ, Eaton EN, Ayyanan A, et al. The epithelial-mesenchymal transition generates cells with properties of stem cells. Cell 2008; 133:704-15.

[37] Li OQ, Xu JD, Wang WJ, Cao XX, Chen Q, et al. Twist1-mediated invasive Adriamycin-induced epithelial-mesenchymal transition relates to multidrug resistance and potential in breast cancer cells. Clin Cancer Res 2009; 15:2657-65.

[38] Cheng GZ, Chan J, Wang Q, Zhang W, Sun CD. Twist transcriptionally upregulates AKT2 in breast cancer cells leading to increased migration, invasion and resistance to Paclitaxel. Cancer Res 2007; 67:1979-87.

[39] Ginestier C, Hur MH, Charafe-Jauffret E, Monville F, Dutcher J, et al. $\mathrm{ALDH} 1$ is a marker of normal and malignant human mammary stem cells and a predictor of poor clinical outcome. Cell Stem Cell 2007; 1:555-67.

[40] Nusse R, Varmus HE. Many tumors induced by the mouse mammary tumor virus contain a provirus integrated in the same region of the host genome. Cell 1982; 31:99-109.

[41] Clevers H, Nusse R. Wnt/ $\beta$-Catenin Signalling and Disease. Cell 2012; 149: 1192-205.

[42] Clark CC, Cohen I, Eichstetter I, et al., Molecular cloning of the human proto- oncogene Wnt-5A and mapping of the gene (WNT5A) to chromosome 3p14-p21. Genomics 1993; 18:249-60.

[43] Prosperi JR, Khramtsov Al, Khramtsova GF, Goss KH. Apc Mutation Enhance PyMT-Induced Mammary Tumorigenesis.PLoS One 2011; 6: e29339.

[44] Ling L, Nurcombe V, Cool SM. Wnt signalling controls the fate of mesenchymal Stem cells. Gene 2009; 433:1-7.

[45] Liu BY, McDermott SP, Khwaja SS and Alexander CM. The transforming activity of Wnt effectors correlates with their ability to induce the accumulation of mammary progenitor cells. ProcNatlAcadSci USA 2004; 101:4158-63.

[46] Many AM , Brown AM. Both canonical and noncanonical Wnt signalling independently promote stem cell growth in mammospheres, PloS One 2014; 9:e101800.

[47] Su YJ, Chang YW, Lin WH., Liang CL, Lee JL. An aberrant nuclear localization of $\varepsilon$-cadherin is a potent inhibitor of $\mathrm{Wnt} / \beta$-catenin-elicited promotion of the cancer stem cell phenotype. Oncogenesis 2015; 4:e157.

[48] Park JI, Venteicher AS, Hong JY, Choi J, Jun S, et al. Telomerase modulates Wnt signalling by association with target gene chromatin. Nature 2009; 460:66-72.

[49] Bafico A, Liu G, Goldin L, Harris V, Aaronson SA. An autocrine mechanism for constitutive Wnt pathway activation in human cancer cells. Cancer Cell 2004; 6:497-506.

[50] Benhaj K, Akcali KC, Ozturk M. Redundant expression of canonical Wnt ligands in human breast cancer cell lines. Oncol Rep 2006; 15:701-7.

[51] Klopocki E, Kristiansen G, Wild PJ, Klaman I, Castanos-Velez E, et al. Loss of SFRP1 is associated with breast cancer progression and poor prognosis in early stage tumors. Int J Oncol 2004; 25:641-9.

[52] Borg JP, Belotti E, Daulat A, Lembo F, Bertucci F, et al. Deregulation of the non-canonical pathway in triple-negative breast cancer. FASEB J 2013; 27:610-1.

[53] Mikels AJ, Nusse R. Purified Wnt5a protein activates or inhibits b- 
catenin-TCF signalling depending on receptor context. PLoSBiol 2004; 4:e115. [54] Grumolato L, Liu G, Mong P, Mudbhary R., Biswas R., et al. Canonical and noncanonicalWnts use a common mechanism to activate completely unrelated coreceptors. Genes Dev 2010; 24:2517-30.

[55] Wehrli M, Dougan ST, Caldwell K, O'Keefe L, Schwartz S, et al. Arrow encodes an LDL-receptor related protein essential for Wingless signalling. Nature 2000; 407:527-30.

[56] Semenov MV, Tamai K, Brott BK, Kuhl M, Sokol S, et al. Head inducer Dickkopf-1 is a ligand for Wnt coreceptor LRP6.Current Biology 2001; 11:951-61.

[57] Zhang X, Hao L, Meng L, Liu M, Zhao L, et al. Digital gene expression tag profiling analysis of the gene expression patterns regulating the early stage of mouse spermatogenesis. PLoS One 2013; 8:e58680.

[58] Wang Y. Wnt/Planar cell polarity signalling: A new paradigm for cancer therapy. Mol Cancer Ther 2009; 8:2103-9.

[59] De A. Wnt/Ca2 + signalling pathway: a brief overview. ActaBiochimBiophys Sin 2011; 43:745-56.

[60] Kirikoshi H, Koike J, Sagara N, Saitoh T, Tokuhara M, et al. Molecular cloning and genomic structure of human Frizzled-3at chromosome 8p21. BiochemBiophys Res Commun 2000;271: 8-14

[61] Masiakowski P and Carroll RD. A novel family of cell surface receptors with tyrosine kinase-like domain. J BiolChem 1992; 267:26181-90.

[62] Katoh M and Katoh M. Identification and characterization of rat RORI and ROR2 genes in silico. Int J Mol Med. 2005; 15:533-8.

[63] Lu X, Borchers AG, Jolicoeur C, Rayburn H, Baker JC, et al. PTK7/CCK-4 is novel regulator of planar cell polarity in vertebrates. Nature 2004; 430:93-8.

[64] Katoh M. Molecular cloning and characterization of Strabismus 2(STB2). Int J Oncol 2002; 20: 993-8.

[65] Katoh M. Structure and expression of Strabismus 1 (STB1) gene on human chromosome lq21-q23. Int J Oncol 2002; 20:1197-203.

[66] Pizzuti A, Novelli G, Mari A, Ratti A, Colosimo A, et al. Human homologue sequences to the Drosophila dishevelled segment-polarity gene are deleted in the DiGeorge syndrome. Am J Hum Genet 1996; 58:722-29.

[67] Greco TL, Sussman DJ and Camper SA. Dishevelled-2 maps to human chromosome 17 and distal to Wnt3a and vestigial tail (vt) on mouse chromosome 11.Mamm Genome 1996; 7:475-76.

[68] Saitoh T, Mine T, Katoh M. Frequent up-regulation of WNT5A mRNA in primary gastric cancer. Int J Mol Med 2002; 9:515-19.

[69] Saitoh T and Katoh M. Molecular cloning and characterization of human WNT5B on chromosome 12pl3.3 region. Int J Oncol 2001; 19:347-51.

[70] Kirikoshi H, Sekihara $H$ and Katoh M. Molecular cloning and characterization of human Wnt11. Int J Mol Med 2001; 8:651-6.

[71] Weeraratna AT, Jiang Y, Hostetter G, Rosenblatt K, Duray, P, et al. Wnt5a signalling directly affects cell motility and invasion of metastatic melanoma. Cancer Cell 2002; 1:279-88.

[72] Willert K, Brown JD, Danenberg E, Duncan AW, Weissman IL, et al. Wnt proteins are lipid-modified and can act as stem cell growth factors. Nature 2003; 423:448-52.

[73] Torres MA, Yang-Snyder JA, Purcell SM, De Marais AA, McGrew LL, et al. Activities of the Wnt-1 class of secreted signalling factors are antagonized by the Wnt-5A class and by a dominant negative Cadherin in early Xenopus development. J Cell Biol 1996; 133:1123-37.

[74] Menck K, Klemm F, Gross JC, Pukrop T, Wenzel D, et al. Induction and transport of Wnt 5 a during macrophage-induced malignant invasion is mediated by two types of extracellular vesicles. Oncotarget 2013; 4:2057-66.

[75] Olson DJ and Gibo DM.. Antisense Wnt-5a mimics Wnt-1-mediated C57MG mammary epithelial cell transformation. Exp Cell Res 1998; 241:134-41.

[76] Jonsson M, Dejmek J, Bendahl PO, Andersson T. Loss of Wnt-5a Protein is associated with early relapse in invasive ductal breast carcinomas. Cancer Res 2002; 62:409-16.

[77] Roarty K and Serra R. Wnt5a is required for proper mammary gland development and TGF- $\{$ beta $\}$-mediated inhibition of ductal growth Development 2007; 134:3929-39.

[78] Li Q, Wu L, Oelschlager DK, Wan M, Stockard CR, Grizzle WE, et al. Smad4 inhibits tumor growth by inducing apoptosis in estrogen receptor-alphapositive breast cancer cells. J Biol Chem. 2005;280(29):27022-8.

[79] Ren Y, Wu L, Frost AR, Grizzle W, Cao X, Wan M. Dual effects of tgf-beta on eralpha-mediated estrogenic transcriptional activity in breast cancer. Mo Cancer. 2009;8:111.

[80] Kessenbrock K, Dijkgraaf GJ, Lawson DA. Littlepage LE, Shahi P, et al. A role for matrix metalloproteinases in regulating mammary stem cell function via the Wnt signalling pathway. Cell Stem Cell 2013; 13:300-13.

[81] McDonald SL, Silver A. The opposing roles of Wnt-5a in cancer. Br J Cancer 2009; 101:209-14.

[82] Hung TH, Hsu SC, Cheng CY, Choo KB, Tseng CP, et al. Wnt5A regulates ABCB1 expression In multidrug-resistant cancer cells through activation of the non-canonical PKA/ 3 -catenin pathway. Oncotarget 2014; 5:12273-90.

[83] Sato A, Yamamoto H, Sakane H, Koyama H and Kikuchi A. Wnt5a regulates distinct signalling pathways by binding to Frizzled2. The EMBO Journal 2010; 29:41-54.

[84] Zhang, S, Chen, L, Cui B, Chuang HY, Yu J, et al. ROR1 is expressed in human breast cancer and associated with enhanced tumor cell growth. PLOS ONE. 2012;7(3):e31127.

[85] Henry C, Quadir A., Hawkins N, Jary E, Llamosas E, et al. Expression of the novel Wnt receptor ROR2 is increased in breast cancer and may regulate both $\beta$-catenin dependent and independent Wnt signalling. J Cancer Res ClinOncol. 2015; 141(2):243-54.

[86] Ansieau S, Bastid J, Doreau A, Morel AP, Bouchet BP, et al. Induction of EMT by twist proteins as a collateral effect of tumor-promoting inactivation of premature senescence. Cancer Cell 2008; 14:79-89.

[87] Cui B, Zhang S, Chen L, Yu J, Widhopf GF 2nd, et al. Targeting ROR1 inhibits epithelial-mesenchymal transition and metastasis. Cancer Research 2013; 73:3649-60.

[88] Gao B. Wht regulation of planar cell polarity (PCP). Current Topics in Developmental Biology 2012; 101:263-295.

[89] Lin Z, Reierstad S, Huang CC, Bulun SE. Novel estrogen receptor-a binding site and estradiol target genes identified by chromatin immunoprecipitation cloning in breast cancer. Cancer Research 2007; 67:5017-24.

[90] Cerami E, Gao J, Dogrusoz U, Gross BE, Sumer SO, et al. The cBio cancer genomics portal: an open platform for exploring multidimensional cancer genomics data. Cancer Discovery 2012; 2:401-4.

[91] Gao J, Aksoy BA, Dogrusoz U, Dresdner G, Gross B, et al. Integrative analysis of complex cancer genomics and clinical profiles using the cBioPortal. Science Signalling 2013; 6:pl1

[92] Anastas JN and Moon RT. WNT signalling pathways as therapeutic targets in cancer. Nature Reviews Cancer 2013;13:11-26.

[93] Gyorffy B, Lanczky A, Eklund AC, Denkert C, Budczies J, et al. An online survival analysis tool to rapidly assess the effect of 22,277 genes on breast cancer prognosis using microarray data of 1,809 patients. Breast Cancer Research and Treatment 2010; 123:725-31.

[94] Kim HJ, Gieske MC, Trudgen KL, Hudgins-Spivey S, Kim BG, et al. Identification of estradio//ERa-regulated genes in the mouse pituitary. Journal of Endocrinology 2011; 210:309-21.

[95] Tao H, Suzuki M, Kiyonari H, Abe T, Sasaoka T, et al. Mouse prickle1, the homolog of a PCP gene, is essential for epiblast apical basal polarity. PNAS 2009; 106:14426-31

[96] Vandenberg AL, Sassoon DA. Non-canonical Wnt signalling regulates cell polarity in female reproductive tract development via van gogh-like2 Development 2009; 136:1559-70.

[97] Luga V, Zhang L, Viloria-Petit AM, Ogunjimi AA, Inanlou MR, et al. Exosomes mediate stromal mobilization of autocrineWnt-PCP signalling in breast cancer cell migration. Cell 2012; 151:1542-56.

[98] Navarro C, Nola S, Audebert S, Santoni MJ, Arsanto JP, et al. Junctional recruitment of mammalian Scribble relies on E-cadherin engagement. Oncogene 2005; 24:4330-9.

[99] Pusztai L, Zhen JH, Arun B, Rivera E, Whitehead C, et al. Phase I and II study of exisulind in combination with capecitabine in patients with metastatic breast cancer. J ClinOncol 2003; 21:3454-61. 